EDITORS' CHOICE

\title{
ASSOCIATIONS OF GENERAL MENTAL HEALTH SYMPTOMS WITH SUBJECTIVE SLEEP QUALITY AND INDIVIDUAL DAYTIME SLEEPINESS*
}

\author{
Schierholz RS ${ }^{1}$, Zavgorodniy I. $^{2}$, Darius S. ${ }^{1}$, Böckelmann $I^{1}$ \\ *Part of the doctoral thesis by Robin Sebastian Schierholz \\ ${ }^{1}$ Institute of Occupational Medicine, \\ Otto von Guericke University Magdeburg, Germany \\ ${ }^{2}$ Kharkiv National Medical University, Ukraine \\ https://doi.org/10.35339/ic.6.4.192-199
}

\begin{abstract}
Purpose: Sufficient sleep quality plays a significant role for long-term physical and mental health. The aim of this study was to examine the associations of general mental health symptoms with sleep quality and daytime sleepiness. Materials and Methods: A cross-sectional survey with 84 included participants (female: $n=42$, male: $n=42$ ) was conducted. General mental health symptoms were assessed using the 12-item General Health Questionnaire (GHQ-12), sleep quality was measured with the Pittsburgh Sleep Quality Index (PSQI), and daytime sleepiness was evaluated with the Epworth Sleepiness Scale (ESS). Statistical differences were calculated using two-sample t-test and Mann-Whitney U test. For correlation analyses Spearman's rank correlation was used. Results: Subjects with poor sleep quality reached higher scores in the GHQ-12 and in the ESS than subjects with good sleep quality, but the difference regarding the ESS was not significant. Higher GHQ-12 scores were associated with higher PSQI scores but not with higher ESS scores. Conclusions: Major findings show strong evidence of an association between general mental health symptoms and sleep quality with poor sleepers having a more disturbed mental health than good sleepers. Further evidence of the interrelationship between subjective sleep quality and general mental health symptoms was found.
\end{abstract}

Keywords: Mental health, Work ability, Stress, Sleep, Insomnia.

\section{Introduction}

Restorative sleep is important for performance, productivity, and efficiency at the workplace as well as for work ability and mental well-being [1]. However, modern society demands permanent flexibility, mobility, and accessibility of the employee. As a consequence, psychological strain at the workplace appears to be an ever larger health hazard. The number of absences due to mental disorders increased sharply compared to other diseases [2].

Corresponding Author:

Robin Sebastian Schierholz, Institute of Occupational Medicine, Otto von Guericke Universi-ty Magdeburg, Leipziger Str. 44, 39120 Magdeburg, Germany. E-mail:iam@med.ovgu.de
Psychological strain leads to an increased physiological and psychological activation [3]. This matter is in contrast to the physiological and psychological reduction of the activation as a main characteristic of sleep [1]. Sleep satisfaction is reduced by social stress [4]. Several studies could find associations between increased work-related psychosocial stress and poor sleep quality [5-8]. Perceived unfair treatment at the workplace is also associated with an increased risk for poor sleep quality in the long run [9].

Disturbed sleep is a symptom of various mental illnesses including bipolar disorder [10] and psychosis [11]. Some sleep problems even form part of the diagnostic criteria of certain psychic illnesses, e.g. major depression or post-traumatic stress disorder [12, 13]. Moreover, for example, regarding clinical depression and anxiety disorder the association between psyche and sleep 
appears to be bidirectional [14-16]. Studies have also shown that sleep disturbances raise the risk for certain mental conditions, e.g. a first episode of psychosis [17], transition to major depression [18], paranoia [19], manic symptoms [20], and burnout [21]. On the other hand, improving sleep problems seem to reduce mental health problems [22].

2. Purposes, subjects and methods:

\subsection{Purpose}

The purpose of the present study was to further investigate the consequences of poor sleep quality on general mental health symptoms and the other way round. We hypothesised that: (1a) bad sleepers have a higher level of daytime sleepiness; (1b) reduced sleep quality is accompanied by higher daytime sleepiness; (2) poor sleep quality is accompanied by reduced general mental health symptoms.

\subsection{Subjects \& Methods \\ Participants and Design}

Participants were recruited through the occupational health out-patient department of the Institute of Occupational Medicine of Otto von Guericke University Magdeburg within the context of regular preventive medical examinations of the employees and via advertisement (distribution of leaflets) both on Health Days and among local undergraduate students. In Germany Health Days are regularly offered in companies within the scope of the operational health management. On these days all employees are invited to participate in various health activities. The recruited participants collected the questionnaires in German at the outpatient department and completed them at home receiving a feedback after handing them in again. All participants except for one were native speakers. Exclusion criteria included shift work, chronic medication intake with influence on the heart rhythm, reported diabetes mellitus, untreated thyroid diseases and treated thyroid diseases with thyroid blood parameters outside the normal range, cardiac diseases, use of nocturnal oxygen or nightly continuous positive airway pressure, and reported diseases of the central or peripheral nervous system resulting in a final study sample of 84 participants of various occupational groups. All subjects provided informed consent prior to participation in the study. Participants' anonymity with consideration for data protection was fully ensured. The study was approved by the ethics committee of Otto von Guericke University Magdeburg (registration no. 50/16) in May 2016. The experimental part of the study was carried out until October 2017.

\section{Questionnaires}

Socio-Demographical and Medical Data

In the beginning participants were asked to give details about age, height and weight (for body mass index; BMI), waist and hip circumference (for waist-hip ratio; WHR), physical activities, job profile, and tobacco consumption. Furthermore, arterial systolic blood pressure (RR sys) and diastolic blood pressure (RR dias) were taken after a 3 to 5-minute stationary phase.

12-Item General Health Questionnaire (GHQ-12)

The GHQ-12 [23, 24], a short version of the $\mathrm{GHQ}$, is an instrument to evaluate general mental health symptoms. It consists of 12 questions screening for recently experienced dysfunctional symptoms and behaviour on a four-stage answerscale. There are 4 different possibilities for scoring [25]. In this study the Likert-scoring (0-3 scale; sum score ranging from $0-36)$ and the dichotomous GHQ-scoring (0-1 scale, 0 in the case of 0 or 1 in the Likert scale or 1 in the case of 2 or 3 in the Likert scale; sum score ranging from 0-12) [26] were used in which a higher value indicates a more disturbed state of psychological health. The cut-off value for disturbed mental health depends on population-specific factors [26-28]. Regarding the GHQ-scoring following Ustun and Sartorius [27] and like in Linden et al. [29] and Seibt et al. [30] a cut-off value of $\geq 5$ was used. With regard to diagnostic validity the GHQ-12 has a sensitivity of $83.4 \%$ and a specificity of $76.3 \%$. The internal consistency is indicated by a Cronbach's alpha coefficient of 0.85 [26].

Pittsburgh Sleep Quality Index (PSQI)

The PSQI [31] is a self-assessment questionnaire capturing subjective sleep quality of the preceding month. It consists of 19 self-rated questions and 5 questions for third-party evaluation not counted in the scoring of the PSQI. The 19 items generate 7 component scores (subjective sleep quality, sleep latency, sleep duration, habitual sleep efficiency, sleep disturbances, use of sleeping medication, daytime dysfunction), each weighted equally on a $0-3$ scale. The sum of the component scores yields the global PSQI score (range of 0-21) in which higher values indicate worse sleep quality. The cut-off value recommended by Buysse et al. [31] to distinguish between good and bad sleepers is $>5$. Regarding diagnostic validity the original study shows a sensitivity of $89.6 \%$ and a specificity of $86.5 \%$, the internal consistency is indicated by a Cronbach's alpha coefficient of 0.83 [31]. 
Epworth Sleepiness Scale (ESS)

The ESS [32] is a self-administered questionnaire assessing daytime sleepiness in recent times. It consists of 8 questions describing different degrees of soporific daily situations for each to be rated the probability to doze off or fall asleep on a scale of $0-3$. If some situations have not been experienced recently subjects are asked to estimate how they might affect them. The 8 selected values are summed to a score (range $0-24$ ) in which higher values indicate a higher level of daytime sleepiness. The determined cutoff value for excessive daytime sleepiness is $>10$ [32-35]. The internal consistency determined by the original author of the ESS is indicated by a Cronbach's alpha coefficient of 0.88 [36]. Referring to diagnostic validity for instance in narcolepsy the ESS has a sensitivity of $93.5 \%$ and a specificity of $100 \%$ [37].

\section{Statistical Analysis}

Regarding descriptive statistics means (M) and standard deviations (SD) as well as medians and ranges were calculated. To test for normal distribution the Kolmogorov-Smirnov test was used. In case of normal distribution and intervalscaled data the two-sample t-test for independent samples was applied. If variables were ordinalscaled or interval-scaled but not normally distributed Mann-Whitney U test was used. When comparing groups for outcomes of interest differences in mean or median are reported with the $95 \%$ confidence interval (95\%CI) in addition to the $p$ value. Pearson's $\chi^{2}$ test was applied if all variables involved were categorial. For correlation analyses we used Spearman's rank correlation since the correlated variables were not normally distributed. The significance level for all analyses was set to $\mathrm{p}<0.05$. All analyses were conducted with the statistical software IBM SPSS Statistics 24, IBM, Armonk, USA.

\section{Results}

On the basis of the reached global PSQI score the participants $(\mathrm{n}=84)$ were divided into the two groups "Good sleepers" ( $n=53$ ) and "Bad sleepers" ( $n=31)$ forming the foundation of the examination with regard to the associations of general mental health symptoms with subjective sleep quality and individual daytime sleepiness.

Socio-Demographical and Medical Data

The participants had a mean age of $37.3 \pm$ 15.6 years (median 33 years, range $19-71$ years), among them 42 females (mean age $38.2 \pm 14.5$ years, median 38.5 years, range $20-71$ years) and 42 males (mean age $36.4 \pm 16.7$ years, median 28 years, range $19-71$ years). The good sleepers consisted of $52.8 \%$ males and $47.2 \%$ females, the bad sleepers of $45.2 \%$ males and $54.8 \%$. Table 1 depicts means and standard deviations of the examined socio-demographical and medical variables for both groups separately and the total sample. The 12 current or former smokers of the good sleepers (23.1\%) smoked an average dose of 10.5 py \pm 9.5 py while the 8 current or former smokers of the bad sleepers (26.6\%) on average smoked a dose of 17.5 py \pm 12.9 py. [Table 1 near here].

\section{Sleep Quality}

Table 2 shows descriptively the average global PSQI scores and the 7 separate component scores with standard deviations as well as the medians and ranges of both groups and the total sample. [Table 2 near here].

The good sleepers needed an average time of 12:13 min \pm 07:55 min to fall asleep (median $10 \mathrm{~min}$, range 2 ? $45 \mathrm{~min}$ ) and actually slept 07:17 $\mathrm{h} \pm$ 00:50 h per night. In comparison the bad sleepers needed on average 35:00 $\mathrm{min} \pm$ 42:04 min to fall asleep (median 23 min, range 2 $240 \mathrm{~min}$ ) and the actual sleep duration was 05:41 $\mathrm{h} \pm$ 01:03 h.

\section{Daytime Sleepiness}

Although the bad sleepers reached higher scores in the ESS no significant difference between the two groups was found $(\mathrm{p}=0.113)$ (table 2). Applying the determined cut-off value for excessive daytime sleepiness of $>10$ [32, 33] no significant distribution was found either $\left(\mathrm{p}_{\chi_{2}}=\right.$ 0.331) (table 3). [Table 3 near here].

While 9 good sleepers $(17.0 \%)$ were categorized as having excessive daytime sleepiness there were 8 bad sleepers (25.8\%), so in total 17 participants scored above the ESS cut-off value.

Correlations between Subjective Sleep Quality and Individual Daytime Sleepiness

Correlating the global PSQI score with the global ESS score no significant association was found $(\mathrm{r}=0.184, \mathrm{p}=0.094)$ (table 4). [Table 4 near here].

Regarding the 7 separate PSQI component scores only the component daytime dysfunction correlated significantly in terms of a very strong evidence with the global ESS score $(r=0.365$, $\mathrm{p}<0.001$ ).

\section{Mental Health Symptoms}

With regard to the global scores in the GHQ-12 a significant difference between the two groups which shows strong evidence was found $(p=0.004)$. The bad sleepers on average reached higher scores (table 2). The distribution after applying 
Table 1

Depiction of the socio-demographical and medical data of both groups

\begin{tabular}{lccc}
\hline & $\begin{array}{c}\text { Good sleepers } \\
(\mathrm{n}=53)\end{array}$ & $\begin{array}{c}\text { Bad sleepers } \\
(\mathrm{n}=31)\end{array}$ & $\begin{array}{c}\text { Total } \\
(\mathrm{n}=84)\end{array}$ \\
\cline { 2 - 4 } & $\mathrm{M} \pm \mathrm{SD}$ & $\mathrm{M} \pm \mathrm{SD}$ & $\mathrm{M} \pm \mathrm{SD}$ \\
Median (range) & Median (range) & $37.3 \pm 15.6$ \\
\hline Age & $35.2 \pm 14.3$ & $40.9 \pm 17.2$ & $33(19-71)$ \\
[years] & $29(19-64)$ & $47(19-71)$ & $24.55 \pm 4.02$ \\
BMI & $24.37 \pm 3.94$ & $24.84 \pm 4.20$ & $23.89(17.63-38.57)$ \\
{$\left[\mathrm{kg} / \mathrm{m}^{2}\right]$} & $23.46(17.63-38.57)$ & $24.13(19.33-34.36)$ & $0.89 \pm 0.11$ \\
WHR & $0.88 \pm 0.11$ & $0.89 \pm 0.11$ & $0.89(0.68-1.29)$ \\
RR sys & $0.89(0.68-1.29)$ & $0.88(0.70-1.20)$ & $125.3 \pm 12.7$ \\
[mmHg] & $125.9 \pm 10.8$ & $124.4 \pm 15.6$ & $124(90-167)$ \\
RR dias & $125(90-158)$ & $121(99-167)$ & $79.1 \pm 9.6$ \\
[mmHg] & $79.3 \pm 8.7$ & $78.8 \pm 11.0$ & $79(57-105)$ \\
Sport & $80.5(60-105)$ & $78(57-102)$ & $2.1 \pm 2.0$ \\
[times/week] & $2.3 \pm 1.9$ & $1.8 \pm 2.0$ & $2(0-8)$ \\
Sport & $2(0-6)$ & $1(0-8)$ & $10.8 \pm 11.1$ \\
[no. of years] & $12.0 \pm 12.2$ & $8.7 \pm 8.9$ & $10(0-45)$ \\
\hline & $10(0-45)$ & $6(0-30)$ & $63(75.0)$ \\
\hline Occupation & & Number $(\%)$ & $6(7.1)$ \\
mainly intellectual & $40(75.5)$ & $23(74.2)$ & $14(16.7)$ \\
mainly physical & $5(9.4)$ & $1(3.2)$ & $1(1.2)$ \\
physical and & $8(15.1)$ & $6(19.4)$ & $15(18.3)$ \\
intellectual & $0(0.0)$ & $1(3.2)$ & $5(6.1)$ \\
pensioner & & $7(23.3)$ & $62(75.6)$ \\
Smoker & $4(15.4)$ & $1(3.3)$ &
\end{tabular}

Table 2

PSQI global and component scores, global ESS scores and global GHQ-12 scores of both groups

\begin{tabular}{|c|c|c|c|c|}
\hline & $\begin{array}{l}\text { Good sleepers } \\
(n=53)\end{array}$ & $\begin{array}{l}\text { Bad sleepers } \\
(n=31)\end{array}$ & $\begin{array}{c}\text { Total } \\
(\mathrm{n}=84)\end{array}$ & Significance \\
\hline & $\begin{array}{c}\mathrm{M} \pm \mathrm{SD} \\
\text { Median (range) } \\
95 \% \mathrm{Cl}\end{array}$ & $\begin{array}{c}\mathrm{M} \pm \mathrm{SD} \\
\text { Median (range) } \\
95 \% \mathrm{Cl}\end{array}$ & $\begin{array}{c}\mathrm{M} \pm \mathrm{SD} \\
\text { Median (range) }\end{array}$ & $\begin{array}{l}\text { p-value } \\
95 \% \mathrm{Cl}\end{array}$ \\
\hline $\begin{array}{c}\text { PSQI } \\
\text { Global PSQI score }\end{array}$ & $\begin{array}{c}3.5 \pm 1.3 \\
4(0-5) \\
3.15-3.92\end{array}$ & $\begin{array}{c}9.0 \pm 2.6 \\
8(6-14) \\
8.08-10.06\end{array}$ & $\begin{array}{l}5.5 \pm 3.3 \\
5(0-14)\end{array}$ & \\
\hline Subjective sleep quality & $\begin{array}{c}0.83 \pm 0.47 \\
1(0-2)\end{array}$ & $\begin{array}{c}1.61 \pm 0.56 \\
2(1-3)\end{array}$ & $\begin{array}{c}1.12 \pm 0.63 \\
1(0-3)\end{array}$ & \\
\hline Sleep latency & $\begin{array}{c}0.58 \pm 0.50 \\
1(0-1)\end{array}$ & $\begin{array}{c}1.58 \pm 0.93 \\
1(0-3)\end{array}$ & $\begin{array}{c}0.95 \pm 0.84 \\
1(0-3)\end{array}$ & \\
\hline Sleep duration & $\begin{array}{c}0.32 \pm 0.51 \\
0(0-2)\end{array}$ & $\begin{array}{c}1.58 \pm 0.96 \\
2(0-3)\end{array}$ & $\begin{array}{c}0.79 \pm 0.94 \\
1(0-3)\end{array}$ & \\
\hline Sleep efficiency & $\begin{array}{c}0.13 \pm 0.40 \\
0(0-2)\end{array}$ & $\begin{array}{c}1.29 \pm 1.11 \\
1(0-3)\end{array}$ & $\begin{array}{c}0.56 \pm 0.93 \\
0(0-3)\end{array}$ & \\
\hline Sleep disturbances & $\begin{array}{c}0.92 \pm 0.34 \\
1(0-2)\end{array}$ & $\begin{array}{c}1.35 \pm 0.49 \\
1(1-2)\end{array}$ & $\begin{array}{c}1.08 \pm 0.45 \\
1(0-2)\end{array}$ & \\
\hline Sleeping medication & $\begin{array}{c}0 \pm 0 \\
0(0-0)\end{array}$ & $\begin{array}{c}0.26 \pm 0.73 \\
0(0-3)\end{array}$ & $\begin{array}{c}0.10 \pm 0.46 \\
0(0-3)\end{array}$ & \\
\hline Daytime dysfunction & $\begin{array}{c}0.72 \pm 0.61 \\
1(0-2)\end{array}$ & $\begin{array}{c}1.35 \pm 0.84 \\
1(0-3)\end{array}$ & $\begin{array}{c}0.95 \pm 0.76 \\
1(0-3)\end{array}$ & \\
\hline $\begin{array}{c}\text { ESS } \\
\text { Global ESS score }\end{array}$ & $\begin{array}{c}7.1 \pm 3.3 \\
7(1-14) \\
5.89-8.16\end{array}$ & $\begin{array}{c}8.8 \pm 4.8 \\
8(0-20) \\
6.68-10.08\end{array}$ & $\begin{array}{l}7.7 \pm 4.0 \\
7(0-20)\end{array}$ & $\begin{array}{c}0.113 \\
0,040-3,475\end{array}$ \\
\hline $\begin{array}{c}\text { GHQ-12 } \\
\text { Global GHQ-12 score }\end{array}$ & $\begin{array}{c}9.1 \pm 3.7 \\
9(3-18) \\
8.45-10.88 \\
\end{array}$ & $\begin{array}{c}12.9 \pm 6.1 \\
11(7-26) \\
10.43-14.81 \\
\end{array}$ & $\begin{array}{l}10.5 \pm 5.0 \\
9(3-26)\end{array}$ & $\begin{array}{c}\mathbf{0 . 0 0 4} \\
1,360-6,182 \\
\end{array}$ \\
\hline
\end{tabular}

p-value: Mann-Whitney U test. 
Table 3

Classification of both groups by applying the ESS cut-off value

\begin{tabular}{llcccc}
\hline & & Good sleepers & Bad sleepers & Total & \\
\cline { 3 - 5 } & & & Number $(\%)$ & \\
\hline ESS & normal & $44(83.0)$ & $23(74.2)$ & $67(79.8)$ & 0.331 \\
& increased & $9(17.0)$ & $8(25.8)$ & $17(20.2)$ & \\
\hline
\end{tabular}

$p$-value: Person's $\chi^{2}$ test.

Correlations of PSQI global and component scores with ESS global score

Table 4 and GHQ-12 global score

\begin{tabular}{|c|c|c|c|c|c|c|c|c|c|}
\hline & & \multicolumn{8}{|c|}{ PSQI components } \\
\hline & & $\begin{array}{l}\frac{0}{0} \\
\stackrel{0}{0} \\
\overline{0} \\
\mathscr{0} \\
\frac{0}{\pi} \\
\frac{0}{0}\end{array}$ & 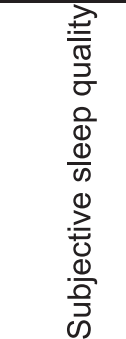 & $\begin{array}{l}\text { d } \\
\frac{\bar{d}}{\omega} \\
\frac{\pi}{0} \\
\frac{\alpha}{\omega}\end{array}$ & 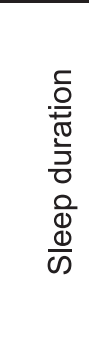 & $\begin{array}{l}\frac{\partial}{0} \\
\frac{\bar{d}}{0} \\
\frac{0}{0} \\
\frac{0}{0} \\
\frac{0}{\omega}\end{array}$ & 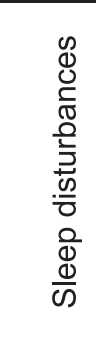 & 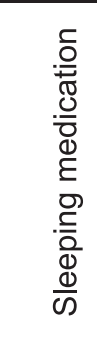 & 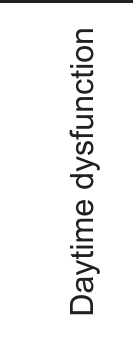 \\
\hline \multirow[t]{2}{*}{ Global ESS score } & $\mathrm{r}$ & 0.184 & 0.115 & 0.017 & 0.066 & 0.070 & 0.211 & 0.011 & 0.365 \\
\hline & $\mathrm{p}$ & 0.094 & 0.300 & 0.880 & 0.550 & 0.530 & 0.054 & 0.921 & $<0.001$ \\
\hline \multirow[t]{2}{*}{ Global GHQ-12 score } & $\mathrm{r}$ & 0.414 & 0.401 & 0.263 & 0.226 & 0.186 & 0.304 & 0.113 & 0.380 \\
\hline & & $<0.001$ & $<0.001$ & 0.016 & 0.039 & 0.090 & 0.005 & 0.304 & $<0.001$ \\
\hline
\end{tabular}

r: Spearman's rank correlation.

the cut-off value for disturbed mental health of $\geq 5$ with regard to the GHQ-scoring [27] shows table 5. [Table 5 near here]. was correlated with the global GHQ-12 score a positive and significant association indicating very strong evidence was found $(\mathrm{r}=0.414, \mathrm{p}<0.001)$.

Table 5

Classification of both groups by applying the GHQ-12 cut-off value

\begin{tabular}{llccc}
\hline & & Good sleepers & Bad sleepers & Total \\
\cline { 3 - 5 } & & & Number (\%) & \\
\hline \multirow{2}{*}{ GHQ } & stable & $51(96.2)$ & $22(71.0)$ & $73(86.9)$ \\
& disturbed & $2(3.8)$ & $9(29.0)$ & $11(13.1)$ \\
\hline
\end{tabular}

The subjects categorised as being good sleepers with stable mental health reached on average a score of $1.1 \pm 1.3$ in the GHQ and 3.5 \pm 1.3 in the PSQI while the subjects categorised as being bad sleepers with disturbed mental health reached on average a score of $7.7 \pm 2.3$ in the GHQ and $11.0 \pm 2.2$ in the PSQI. Categorised good sleepers with disturbed mental health reached on average a score of $7.0 \pm 0.0$ in the GHQ and $4.0 \pm 1.5$ in the PSQI, categorised bad sleepers with stable mental health reached on average a score of $1.0 \pm 1.0$ in the GHQ and 8.2 \pm 2.3 in the PSQI.

Correlations between General Mental Health Symptoms and Subjective Sleep Quality as well as Individual Daytime Sleepiness

Correlation analyses were performed to find further associations of general mental health symptoms with subjective sleep quality and daytime sleepiness. When the global PSQI score
Apart from the components sleep efficiency and sleeping medication the component scores correlated significantly with the global GHQ-12 score as well (table 4). However, correlating the global ESS score with the global GHQ-12 score no significant relation was found $(\mathrm{r}=0.118$, $\mathrm{p}=0.285$ ).

\section{Discussion}

There is a rise of mental strain in the world of work [2]. Sleep disturbances and problems falling asleep are often associated with occupational stress as well as problems and social conflicts at the workplace [5-9].

Restorative sleep plays a significant role for health, subjective well-being, and quality of life $[38,39]$. Due to the unconscious experience sleep and its quality can subjectively only be assessed in retrospect [40]. In this study the PSQI was used for that which distinguishes between good and bad sleepers. This distinction was used to 
divide the total sample into two groups ("Good sleepers" and "Bad sleepers").

General mental health symptoms assessed with the GHQ-12 differed significantly in terms of a strong evidence between both groups whereby the bad sleepers had a worse psychological state in form of higher scores in the GHQ-12. In the correlation analyses significant positive associations between the global GHQ-12 score and the global PSQI score as well as most PSQI component scores were found, too. These associations were both of weak, strong, and very strong evidence.

Given the cross-sectional design of this study it is not possible to draw any conclusions regarding the causality of the associations. It might both be conceivable that subjective sleep quality had an influence on mental health and that mental health influenced subjective sleep quality. It is probable that there is a bidirectional relationship since on the one hand disturbed sleep is symptom of various psychic illnesses [16], but on the other hand it also causes psychic illnesses [14, 15]. Short sleep duration is associated with burnout [41], depression, and suicidal tendency [42, 43]. Kahn-Greene et al. [44] could show that there is an increase of depressive symptoms already after 56 hours of sleep deprivation. The association of psyche and sleep could also be illustrated by the fact that behavioural therapy procedures are superior to hypnotics in the treatment of particular sleep disorders [45, 46]. Cognitive behavioural therapy for insomnia also improves comorbid anxiety and depression [22, 47]. Mental health can be influenced by work-related psychosocial stress. Various studies found a significant association between social stress as well as workrelated psychosocial stress and sleep quality [4$6,8]$. A specific problem could be the current development towards permanent availability of the employee. After regular work working is virtually continued due to permanent availability what leads to qualitative and quantitative disturbance of sleep [48]. The results of this study show that poor mental health is associated with reduced sleep quality. Improving sleep might enhance mental health and thus the work ability of the employee. On the other hand, improving mental health could lead to better sleep and thus to a better recovered and more efficient employee.

A possibility of distortion of the described associations in this study could be that a subject with poor mental health or poor subjective sleep quality might have a negative and pessimistic general attitude and therefore estimates the respective other factor intentionally or unintentionally worse than it actually is. In comparison the subject with good psychological health or good subjective sleep quality possibly could have a positive and optimistic general attitude and evaluates the respective other factor intentionally or unintentionally better than it actually is.

The GHQ-12 is an instrument to assess recently experienced mental dysfunctional symptoms and behaviour. A further more precise psychopathological exploration was not performed. Therefore, it cannot be estimated if psychological health was disturbed before recent times or since when it was damaged. That is why we are not able to say from what period of time the association of mental health and sleep quality might possibly exist.

To our knowledge there are few studies which examine the associations of subjective sleep quality and daytime sleepiness with the GHQ score or the GHQ classification. One study which examined students in southern Thailand confirmed the association between poor sleep quality and mental health problems in their sample [49]. The prevalence of poor sleep quality in this study was $42.4 \%$. Sepehrmanesh [50] also showed that sleep quality might play a significant role in various aspects of mental health. There were significant correlations between general mental health symptoms, physical symptoms, states of anxiety, depression and sleep quality. Both studies used a relatively young sample.

Limitations of this study are the crosssectional design and the relatively small sample size, especially for the categorical group comparisons. Moreover, the study relied on selfreport questionnaires which were completed at home. The clinical relevance of the 95\%CI of the results of this study is small. Extended diagnostics (e.g. sleep laboratory) might be necessary to evaluate them sufficiently. Further research on this topic including studies with longitudinal design and larger sample sizes is required. On the whole the findings of this study might provide further evidence of the interrelationship between subjective sleep quality and mental health and could emphasise the important role of restorative sleep for psychological wellbeing and the other way round.

\section{Declaration}

The authors report no conflicts of interest.

\section{Data Availability}

The data that support the findings of this study are available from the corresponding author, RSS, upon reasonable request. 


\section{References}

1. Åkerstedt, T. (2006). Psychosocial stress and impaired sleep. Scand J Work Environ Health, 32, 493-501.

2. Bauer, J. (2016). Psychische Belastungen am Arbeitsplatz: Rechtliche Rahmenbedingungen [Mental stress at the workplace: Legal framework conditions]. Zbl Arbeitsmed, 66, 47-49.

3. Selye, H. (1956). The Stress of Life. New York (NY): McGraw-Hill.

4. Schulz, P., Hellhammer, J., Schlotz, W. (2003). Arbeitsstress, sozialer Stress und Schlafqualität: Differentielle Effekte unter Berücksichtigung von Alter, Besorgnisneigung und Gesundheit [Work stress, social stress, and sleep quality: Differential effects in consideration of age, worry disposition, and health]. Zeitschrift fur Gesundheitspsychologie, 11, 1-9.

5. Kalimo, R., Tenkanen, L., Harma, M. (2000). Job stress and sleep disorders: findings from the Helsinki Heart Study. Stress Health, 16, 65-75.

6. Åkerstedt, T., Fredlund, P., Gillberg, M. (2002). Work load and work hours in relation to disturbed sleep and fatigue in a large representative sample. J Psychosom Res, 53,585-588.

7. De Lange, A. H., Kompier, M. A., Taris, T. W. (2009). A hard day's night: a longitudinal study on the relationships among job demands and job control, sleep quality and fatigue. J Sleep Res, 18, 374-383.

8. Åkerstedt, T., Nordin, M., Alfredsson, L. (2012). Predicting changes in sleep complaints from baseline values and changes in work demands, work control, and work preoccupation - The WOLFproject. Sleep Med, 13, 73-80.

9. Elovainio, M., Ferrie, J.E., Gimeno, D. (2009). Organizational Justice and Sleeping Problems: The Whitehall II Study. Psychosom Med, 71, 334-340.

10. Harvey, A.G., Schmidt, D.A., Scarná, A. (2005). Sleep-Related Functioning in Euthymic Patients With Bipolar Disorder, Patients With Insomnia, and Subjects Without Sleep Problems. Am J Psychiatry, 162, 50-57.

11. Freeman, D., Pugh, K., Vorontsova, N. (2009). Insomnia and paranoia. Schizophr Res., 108, 280-284.

12. (2013). American Psychiatric Association. Diagnostic and Statistical Manual of Mental Disorders Fifth edition (DSM-5). Arlington (VA): American Psychiatric Publishing.

13. (2016).World Health Organization. International Statistical Classification of Diseases and Related Health Problems $-10^{\text {th }}$ Revision (ICD-10). Geneva: World Health Organization.

14. Breslau, N., Roth, T., Rosenthal, L. (1996). Sleep Disturbance and Psychiatric Disorders: A Longitudinal Epidemiological Study of Young Adults. Biol Psychiatry, 39, 411-418.

15. Chang, P.P., Ford, D.E., Mead, L.A. (1997). Insomnia in Young Men and Subsequent Depression: The Johns Hopkins Precursors Study. Am J Epidemiol, 146, 105-114.

16. Krystal, A.D. (2012). Psychiatric Disorders and Sleep. Neurol Clin., 30, 1389-1413.

17. Ruhrmann, S., Schultze-Lutter, F., Salokangas, R.K. (2010). Prediction of Psychosis in Adolescents and Young Adults at High Risk: Results From the Prospective European Prediction of Psychosis Study. Arch Gen Psychiatry, 67, 241-251.

18. Buysse, D.J, Angst, J., Gamma, A. (2008). Prevalence, Course, and Comorbidity of Insomnia and Depression in Young Adults. Sleep, 31, 473-480.

19. Freeman, D., Stahl, D., McManus, S. (2012). Insomnia, worry, anxiety and depression as predictors of the occurrence and persistence of paranoid thinking. Soc Psychiatry Psychiatr Epidemiol., 47, 1195-1203.

20. Kaplan, K.A., McGlinchey, E.L., Soehner, A. (2015). Hypersomnia subtypes, sleep and relapse in bipolar disorder. Psychol Med, 45, 1751-1763.

21. Elfering, A., Kottwitz, M.U., Tamcan, Ö. (2018). Impaired sleep predicts onset of low back pain and burnout symptoms: evidence from a three-wave study. Psychol Health Med., 23, 1196-1210.

22. Freeman, D., Sheaves, B., Goodwin, G.M. (2017). The effects of improving sleep on mental health (OASIS): a randomised controlled trial with mediation analysis. Lancet Psychiatry., 4, 749-758.

23. Goldberg, D.P. (1972). The Detection of Psychiatric Illness by Questionnaire: A Technique for the Identification and Assessment of Non-Psychotic Psychiatric Illness. London (UK): Oxford University Press.

24. Goldberg, D. P. (1978). Manual of the General Health Questionnaire. Windsor (UK): NFER.

25. Goldberg, D.P., Williams, P. (1988). A User's Guide to the General Health Questionnaire. Windsor (UK): NFER.

26. Goldberg, D.P, Gater, R., Sartorius, N. (1997). The validity of two versions of the GHQ in the WHO study of mental illness in general health care. Psychol Med., 27, 191-197. 
27. Ustun, T.B., Sartorius, N. (1995). Mental Illness in General Health Care: An International Study. Chichester (UK): John Wiley \& Sons.

28. Goldberg, D.P., Oldehinkel, T., Ormel, J. (1998). Why GHQ threshold varies from one place to another. Psychol Med., 28, 915-921.

29. Linden, M., Maier, W., Achberger, M. (1996). Psychische Erkrankungen und ihre Behandlung in Allgemeinarztpraxen in Deutschland: Ergebnisse aus einer Studie der Weltgesundheitsorganisation (WHO) [Psychological disorders and their treatment in general praxis in Germany: Results of a World Health Organization (WHO) study]. Nervenarzt, 67, 205-215.

30. Seibt, R., Matz, A., Hegewald, J. (2011). Working conditions of female part-time and full-time teachers in relation to health status. Int Arch Occup Environ Health, 85, 675-687.

31. Buysse, D.J., Reynolds, C.F., Monk, T.H. (1989). The Pittsburgh Sleep Quality Index: A New Instrument for Psychiatric Practice and Research. Psychiatry Res., 28, 193-213.

32. Johns, M.W. (1991). A New Method for Measuring Daytime Sleepiness: The Epworth Sleepiness Scale. Sleep, 14, 540-545.

33. Johns, M.W., Hocking, B. (1997). Daytime Sleepiness and Sleep Habits of Australian Workers. Sleep., 20, 844-849.

34. Bloch, K.E., Schoch, O.D., Zhang, J.N. (1999). German Version of the Epworth Sleepiness Scale. Respiration, 66, 440-447.

35. Sauter, C., Popp, R., Danker-Hopfe, H. (2007). Normative values of the German Epworth Sleepiness Scale. Somnologie (Berl)., 11, 272-278.

36. Johns, M.W. (1992). Reliability and Factor Analysis of the Epworth Sleepiness Scale. Sleep, 15, 376-381.

37. Johns, M.W. (2000). Sensitivity and specificity of the multiple sleep latency test (MSLT), the maintenance of wakefulness test and the Epworth sleepiness scale: Failure of the MSLT as a gold standard. J Sleep Res., 9, 5-11.

38. Happe, S. (2011). Schlaf und seine St?rungen im Alter [Sleep and its disorders in the elderly]. Bundesgesundheitsblatt Gesundheitsforschung Gesundheitsschutz, 54, 1311-1318.

39. Buysse, D.J. (2014). Sleep Health: Can We Define It? Does It Matter? Sleep., 37, 9-17.

40. Heitmann, J., Cassel, W., Ploch, T. (2011). Messung von Schlafdauer und Schlafqualit?t [Measuring sleep duration and sleep quality]. Bundesgesundheitsblatt Gesundheitsforschung Gesundheitsschutz, 54, 1276-1283.

41. Soderstrom, M., Jeding, K., Ekstedt, M. (2012). Insufficient Sleep Predicts Clinical Burnout. J Occup Health Psychol., 17, 175-183.

42. Goodwin, R.D., Marusic, A. (2008). Association Between Short Sleep and Suicidal Ideation and Suicide Attempt Among Adults in the General Population. Sleep.,31,1097-1101.

43. Gangwisch, J.E., Babiss, L.A., Malaspina, D. (2010). Earlier Parental Set Bedtimes as a Protective Factor Against Depression and Suicidal Ideation. Sleep., 33, 97-106.

44. Kahn-Greene, E.T., Killgore, D.B., Kamimori, G.H. (2007). The effects of sleep deprivation on symptoms of psychopathology in healthy adults. Sleep Med., 8, 215-221.

45. Jacobs, G.D., Pace-Schott, E.F., Stickgold, R., (2004). Cognitive Behavior Therapy and Pharmacotherapy for Insomnia: A Randomized Controlled Trial and Direct Comparison. Arch Intern Med., 164, 1888-1896.

46. Trauer, J.M., Qian, M.Y., Doyle, J.S. (2015). Cognitive Behavioral Therapy for Chronic Insomnia: A Systematic Review and Meta-analysis. Ann Intern Med., 163, 191-204.

47. Ye, Yy., Zhang, Y.f, Chen, J. (2015). Internet-Based Cognitive Behavioral Therapy for Insomnia (ICBT-i) Improves Comorbid Anxiety and Depression - A Meta-Analysis of Randomized Controlled Trials. PLoS One., 10, e0142258.

48. Wuyts, J., De Valck, E., Vandekerckhove, M. (2012). Effects of pre-sleep simulated on-call instructions on subsequent sleep. Biol Psychol., 91, 383-388.

49. Pensuksan, W.C., Lertmaharit, S., Lohsoonthorn, V. (2016). Relationship between Poor Sleep Quality and Psychological Problems among Undergraduate Students in the Southern Thailand. Walailak J Sci Technol., 13, 235-242.

50. Sepehrmanesh, Z. (2016). The relation between sleep quality and mental health in students of Kashan University of Medical Sciences. Eur Psychiatry, 33, S743.

Received: 13-Sep-2019 Accepted: 13-Dec-2019 